The finding of an improved prognosis in gastric cancers expressing $c$-erbB-2 protein is also in contrast to most studies in breast cancer ${ }^{4}$ where expression has been associated with a shorter relapse time and survival. The functional role of $c-e r b \mathrm{~B}-2$ protein in gastric carcinoma is unknown and overexpression only occurs in a proportion of tumours. It may be related to a specific mechanism of transformation occurring in better differentiated carcinomas, although further studies are needed to clarify this.

1 Yamamoto T, Ikawa S, Akiyama T, et al. An erb-B-related gene, c-erbB-2, encodes a possible receptor protein simila to the epidermoid growth factor receptor. Nature 1986 319:230-4

2 Tal M, Wetzler M, Josefberg Z, et al. Sporadic amplification of the Her 2 /neu proto-oncogene in adenocarcinomas of various tissues. Cancer Res 1988;48:1517-20.
3 Walker RA, Senior PV, Jones JL, Critchley DR, Varley JM An immunohistochemical and in situ hybridisation study Af c-myc and c-erbB-2 expression in primary human breast carcinomas. J Pathol 1989;158:97-105.

4 Wright C, Angus B, Nicholson S, et al. Expression of c-erbB-2 oncoprotein: a prognostic indicator in breast c-erbB-2 oncoprotein: a prognostic

5 Falck VG, Gullick WJ. c-erb-2 oncogene product staining in gastric adenocarcinoma. An immunohistochemical study. Pathol 1989;159:107-11.

6 Jain S, Filipe IM, Gullick WJ, Lineham J. Does c-erbB-2 expression have prognostic significance in gastric carcinoma? J Pathol 1990;161:343A.

7 Yonemura Y, Ninoniya I, Yamaguchi A, et al. Evaluation of immunoreactivity for erbB-2 protein as a marker of poor short term prognosis in gastric cancer. Cancer Res 1991;51:1034-8.

8 Gullick WJ, Berger MS, Bennett PLP, Rothbard JB, Waterfield MD. Expression of c-erbB-2 protein in normal and transformed cells. Int $J$ Cancer 1987;40:246-54.

9 Park JB, Rhim JS, Park SC, Kimm SW, Kraus MH. Amplification, overexpression, and rearrangement of Amplification, overexpression, and rearrangement of the erB2-2 proto oncogene in primary

10 Yokota J, Yamamoto T, Miyajimia N, et al. Genetic alterations of the c-erbB-2 oncogene occur frequently in tubular adenocarcinoma of the stomach and are often accompanied by amplification of the v-erbA homologue. Oncogene 1988;2:283-7.

\title{
Histological audit of acute appendicitis
}

\author{
M E Herd, P A Cross, S Dutt
}

\begin{abstract}
One hundred retrospective appendectomy specimens were examined in an attempt to study the degree of uniformity and clarity of reporting of this common surgical specimen. There was full agreement in 73 cases and some degree of discrepancy in 27 cases. It is suggested that greater clarity in reporting can be achieved with five reporting categories: (i) established acute inflammation; (ii) no evidence of acute inflammation ("normal"); (iii) features suggestive of early inflammation; (iv) peri-appendicitis; (v) other features, such as granulomata, Enterobius vermicularis, tumours, etc.
\end{abstract}

Some 70000 appendectomies are performed each year in England and Wales ${ }^{1}$ for a clinical diagnosis of acute appendicitis. This makes the appendix one of the more commonly received specimens in a histology department. This ensures that histopathologists should see a regular number of these specimens a year, but does not guarantee that they agree on what they see, or on interpretation. With the current emphasis on medical audit, ${ }^{23}$ we felt that the routine reporting of these appendix specimens required a new look with two main aims: (i) can histopathologists report appendix specimens consistently? and (ii) if not, why not?

\section{Methods}

The surgical pathology files of our department were searched and 100 retrospective consecutive appendix histology slides and their reports were withdrawn. All the specimens were from the period January to September 1990. The initial slides had been reported by six different histologists during the study period, all post-MRCPath. The slides were reviewed blind by three consultant histopathologists with no macroscopic or clinical details. The issued reports and those of the reviewing pathologists were then compared and any differences noted.

\section{Results}

Of the 100 study appendices, 90 were removed for a clinical diagnosis of acute appendicitis, four for persistent right illiac fossa pain, and six as part of another procedure. The average number of pieces of tissue taken from each appendix was four (including the tip and proximal resection margin), with a range of two to 13 . Of the 100 appendix specimens reviewed, there was complete agreement between the three reviewing pathologists and that of the initial issued report in 73 cases, with the agreed diagnoses being established acute inflammation in 56 cases; no evidence of acute inflammation in 13 cases; early inflammation in two cases; periappendicitis in two cases, and with one case also containing Enterobius vermicularis. In 27 cases
Correspondence to: Dr P Cross

Accepted for publication 18 September 1991

Department of
Histopathology, Bury
General Hospital,
Walmersley Road,
Bury, Lancashire
BL96PG
M E Herd
P A Cross
S Dutt
Correspondence to:
Dr P Cross
Accepted for publication
18 September 1991


Table 1 Agreement among pathologists

\begin{tabular}{|c|c|c|c|c|}
\hline \multirow{2}{*}{$\begin{array}{l}\text { Case } \\
\text { No }\end{array}$} & \multicolumn{3}{|l|}{ Pathologist } & \multirow[b]{2}{*}{ Issued report } \\
\hline & 1 & 2 & 3 & \\
\hline 1 & Acute & ?Resolving & Peri-app & Early \\
\hline 2 & Early & Normal & ?Early & Normal \\
\hline 3 & Early & Early & ?Resolving & Early \\
\hline 4 & Normal & Early & Peri-app & Early \\
\hline 5 & Early & Acute & Acute & Acute \\
\hline 6 & Normal & Early & Normal & Early \\
\hline 7 & Nil acute diverticulae & Nil acute diverticulae & Nil acute diverticulae & Nil acute endometriosis \\
\hline 8 & Nil acute & Nil acute & Nil acute & Sub-acute \\
\hline 9 & Acute hyperplasia & Acute hyperplasia & Acute villous adenoma & Acute villous adenoma \\
\hline 10 & Normal & ?Resolving & Nil acute & Nil acute \\
\hline 11 & Normal & Early & ?Sub-acute & Early \\
\hline 12 & ?Early & Normal & Normal & Early \\
\hline 13 & Normal & Resolving metaplasia & Normal & Resolving metaplasia \\
\hline 14 & Early & ?Resolving & ?Early & Early \\
\hline 15 & Normal & Resolving & Normal & Normal \\
\hline 16 & Normal & PResolving & $\begin{array}{l}\text { Normal } \\
\text { ?Villous change }\end{array}$ & Resolving sub-acute \\
\hline 17 & Normal & Normal & Focal foreign body response (serosa) & Normal \\
\hline 18 & Normal evermicularis & Normal evermicularis & Normal evermicularis & Mild acute evermicularis \\
\hline 19 & ?Acute & ?Peri-app & Peri-ape & Sub-acute \\
\hline 20 & Normal & ?Sub-acute & Normal & Early \\
\hline 21 & Normal & ?Resolving & Normal & Early \\
\hline 22 & Acute evermicularis & Acute evermicularis & Acute evermicularis & Acute \\
\hline 23 & ?Early & Early & Mild serosal & Early \\
\hline 24 & ?Early & Normal & Normal & Normal \\
\hline 25 & Normal & ?Resolving & Normal & Early \\
\hline 26 & Acute & Acute & Acute ?granuloma & Acute \\
\hline 27 & Acute & Acute metaplasia & Acute villous adenoma & Acute metaplasia \\
\hline
\end{tabular}

Bold underlined, pathologist who issued original surgical report.

If not specified, report issued by another pathologist (one of three)

?f not specified, report

?, probable diagnosis.

Normal, no evidence of acute inflammation, "normal" appearance.

Peri-app, peri-appendiceal inflammation, probably extrinsic to appendix.

Hyperplasia,

Metaplasia,

Villous adenoma

changes present in mucosa

Evermicularis, Enterobius vermicularis.

Resolving, possible resolving acute inflammation.

Sub-acute, low grade inflammation.

Table 2 Age/sex distribution of patients with appendicectomies studied

\begin{tabular}{llccccccccc}
\hline Age & & $0-9$ & $10-19$ & $20-29$ & $30-39$ & $40-49$ & $50-59$ & $60-69$ & $70-79$ & $80-89$ \\
Sex & $M$ & 2 & 23 & 12 & 2 & 1 & 2 & 0 & 1 & 2 \\
& $F$ & 1 & 26 & 12 & 4 & 7 & 3 & 1 & 0 & 1 \\
\hline
\end{tabular}

there was at least one disagreement among the pathologists (table 1). The patient population studied is shown in table 2 . On review of the patient notes for all of these 100 cases, there was no difference in symptoms, hospital stay, or post-operative complications between the discrepant group of 27 cases and that of the agreed 73 cases. The histological report was issued within two days in most cases, but was slightly longer in 35 cases (three to four days), largely due to the taking of further material. There was no evidence that the speed of return of the histological report delayed or interfered with clinical action. The histological report was not present in five of the clinical notes.

\section{Discussion}

In this study of 100 consecutive resected appendices there was complete agreement on the histological features in 73 cases. In the other 27 cases there was some level of disagreement. These disagreements can be divided into two broad categories: (i) those not related to inflammation (cases $7,9,13,16,17$, $18,26,27$ ); and (ii) those related to minor degrees of inflammation (the remaining cases including cases 13 and 16). In 18 of these
27 cases the terms "normal", "early", "subacute" or "resolving" were used-that is, there was no definite evidence of any established acute inflammation. The terms "sub-acute" and "resolving" are difficult to define but seem to be interpretations of groups of luminal/ intraglandular polymorphs or chronic inflammatory cells in the submucosa/muscularis, while "early" acute inflammation is interpreted by some in the presence of minor groups of mucosal/luminal polymorphs with or without mucosal ulceration. ${ }^{4-7}$ The last three terms are subjective interpretations of minor degrees of inflammation seen histologically and can be confusing to both histologists and surgeons alike. This confusion can be avoided, and more uniformity and clarity achieved with five reporting categories: (i) established acute inflammation; (ii) no evidence of acute inflammation ("normal"); (iii) features suggestive of early inflammation, (iv) peri-appendicitis; (v) other features, such as granulomata, Enterobius vermicularis, tumours, etc.

These are defined as follows:

(i) mucosal ulceration, transmural polymorph infiltrate, often with mural necrosis and a serosal inflammatory response; 
(ii) no evidence of any inflammation (no features of $i$, iii, or iv);

(iii) focal true mucosal ulceration with polymorphs

(iv) serosal/peri-appendicular inflammation (usually with polymorphs) with no evidence of any appendiceal mucosal/submucosal inflammation;

(v) features as mentioned, with the noncarcinoid tumours being described as outlined by Williams and Whitehead. ${ }^{8}$

These distinct groups ought to remove the situation seen in this study where, with the previously used terms, the reviewing pathologist disagreed with their own initial interpretation in 15 cases. However, this was never enough to alter a case to, or from, a definite "acute" diagnosis. Those appendices which show no evidence of any acute inflammation fall into the "normal" category, in that no features are seen to account for the clinical symptoms. We are now using these five categories for reporting appendices, and they are preferred by our requesting surgeons.

These categories indicate clearly if there is an early or acute appendicitis, and that the clinical symptoms are due to the appendix. If there is peri-appendicitis then the cause for the peritonitis (pelvic inflammatory disease, perforated bowel, etc) must be sought. If the appendix exhibits no inflammation at all ("normal") then, again, the cause for the symptoms probably lies outside of the appendix, although Enterobius vermicularis could account for appendiceal related pain in the absence of histological inflammation. This study also highlights the difficulty in deciding exactly what constitutes an early true appendicitis as minor degrees of inflammation can be seen in appendices from patients with no clinical symptoms. ${ }^{45}$ At present, category iii has to be defined by focal true mucosal ulceration with polymorphs. We are currently undertaking a detailed histological study of appendices in an attempt to define features which can be used to diagnose such true early intrinsic appendiceal inflammation prior to mucosal ulceration, and this will be reported shortly.

1 OHE. Office of Health Economics compendium of health statistics. London: HMSO, 1982.

2 Ramsay AD. Locally organised medical audit in histopathology. J Clin Pathol 1991;44:353-7.

3 Shaw CD, Costain DW. Guidelines for medical audit: seven principles. Br Med J 1989;299:498-9.

4 Campbell JS, Fornier P, DaSilva T. When is the appendix normal? Can Med Assoc J 1961;85:1155-7.

5 Touloukian RJ, Trainer TD. Significance of focal inflammation of the appendix. Surgery 1964;56:942-4

6 Lau WY, Fan ST, Yiu TF, Chu KW, Suen HC, Wong KK The clinical significance of routine histopathologic study of the resected appendix and safety of appendiceal inversion. Surg Gynecol Obstet 1986;162:256-8.

7 Butler C. Surgical pathology of acute appendicitis. Hum Pathol 1981;12:870-8.

8 Williams RA, Whitehead R. Non-carcinoid epithelial tumours of the appendix - a proposed classification. Pathology 1986;18:50-3. 